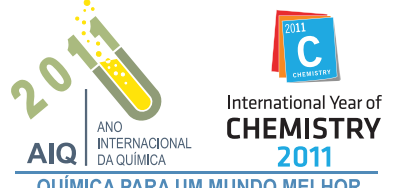

\title{
ARTIGOS DA REVISTA CIÊNCIA HOJE COMO RECURSO DIDÁTICO NO ENSINO DE QUÍMICA
}

\author{
Luciana Nobre de Abreu Ferreira \\ Universidade Federal de São Carlos, Rod. Washington Luís, km 235, 13565-905 São Carlos - SP, Brasil \\ Salete Linhares Queiroz* \\ Instituto de Química de São Carlos, Universidade de São Paulo, CP 780, 13560-970 São Carlos - SP, Brasil
}

Recebido em 9/5/10; aceito em 21/8/10; publicado na web em 26/10/10

\begin{abstract}
CIÊNCIA HOJE ARTICLES AS A DIDATIC TOOL IN CHEMISTRY TEACHING. This paper presents the results from the selection and analysis of Ciência Hoje articles published from 2004 to 2009 with the aim to discuss some of their features which can assist teachers in chemistry teaching. Therefore, the articles were analyzed according to their content and format based on an analytical tool proposed by Kawamura and colleagues. The results indicate that this magazine offers a reasonable collection of articles related to chemistry with a variety of contents and approaches.
\end{abstract}

Keywords: chemistry education; popular science texts; Ciência Hoje magazine.

\section{INTRODUÇÃO}

Estudos têm demonstrado o interesse da comunidade de pesquisadores em educação em ciências no funcionamento de textos de divulgação científica (TDCs) no ambiente escolar, a partir de uma variedade de perspectivas e pontos de vista. ${ }^{1-4}$ Esses pesquisadores destacam a importância da introdução de textos dessa natureza em aulas de ciências, ao afirmarem que a sua utilização pode contribuir, entre outros aspectos, para que os alunos: formem uma imagem adequada e crítica da ciência enquanto produção humana; discutam as suas aplicações tecnológicas presentes no cotidiano e as implicações sociais decorrentes do seu uso; tenham acesso a uma maior diversidade de informações; desenvolvam habilidades de leitura e de formas de argumentação; dominem conceitos e compreendam melhor elementos de terminologia científica.

Tal interesse encontra respaldo em recomendações curriculares que encorajam o uso de uma diversidade de textos na sala de aula de ciências e enfatizam os benefícios advindos de sua leitura para a aquisição de vocabulário e entendimento conceitual:

Além do livro didático, outras fontes oferecem textos informativos: enciclopédias, livros para-didáticos, artigos de jornais e revistas, folhetos de campanhas de saúde, de museus, textos da mídia informatizada, etc. É importante que o aluno possa ter acesso a uma diversidade de textos informativos, pois cada um deles tem estrutura e finalidades próprias. Trazem informações diferentes, e muitas vezes divergentes, sobre um mesmo assunto, além de requererem domínio de diferentes habilidades e conceitos para sua leitura. ${ }^{5}$

Pesquisas que tratam da análise de TDCs publicados em revistas de divulgação científica apontam suas potencialidades didáticas no apoio ao ensino formal, especialmente no sentido de contribuir para a construção de um conhecimento abrangente e contextualizado em sala de aula. ${ }^{6-8}$ Segundo os autores, ainda que o destinatário da revista seja o público em geral, há um endereçamento bastante evidente para professores e alunos, principalmente em função das temáticas envolvidas nesses textos. Ademais, a maioria dos artigos apresenta

*e-mail: salete@iqsc.usp.br forte tendência em abordar assuntos que têm relação direta com a saúde e o cotidiano dos leitores.

Tendo em vista o potencial didático de TDCs no ensino de ciências, existe a necessidade de contribuições por pesquisadores da área para que discussões a respeito da temática progridam. Nessa perspectiva, no presente artigo apresentamos resultados de um trabalho de seleção e análise de TDCs direta ou indiretamente ligados à química publicados na revista Ciência Hoje, entre 2004 e 2009, com o intuito de oferecermos elementos capazes de subsidiar professores na escolha desse tipo material para uso em sala de aula.

A análise dos artigos foi realizada tendo como base o instrumento de análise proposto por Kawamura e colaboradores, ${ }^{9,10}$ no qual são considerados o conteúdo e a forma dos TDCs. Neste manuscrito apresentamos um panorama geral a respeito da presença de artigos relacionados à química na revista, assim como a análise detalhada do artigo intitulado "Eletricidade estática: onde ficam as cargas?", publicado em setembro de 2004.

A escolha da revista Ciência Hoje se justifica pelo fato de a mesma possuir excelente reputação no meio acadêmico, ser constantemente atualizada e constituir-se um veículo de matérias da atualidade e de interesse social. Além disso, possui fácil acesso pelos professores, pois costuma estar presente em bibliotecas públicas e escolas do nível básico. Como primeira revista de divulgação científica do país, tem contribuído significativamente para a difusão e o desenvolvimento do conhecimento científico, conforme discutimos no tópico a seguir.

\section{REVISTA CIÊENCIA HOJE}

A revista Ciência Hoje é uma publicação do Instituto Ciência Hoje, organização social de interesse público vinculada à Sociedade Brasileira para o Progresso da Ciência (SBPC). Pode ser considerada como de divulgação científica, uma vez que é assim denominada por seus editores: sua capa traz a frase "Revista de divulgação científica da SBPC". A revista Ciência Hoje oferece um panorama completo da produção intelectual e tecnológica das universidades, institutos e centros de pesquisa nacionais e dos avanços da ciência internacional e se dirige à comunidade acadêmica, aos professores e estudantes de ensino médio e à sociedade em geral. Segundo Dias, ${ }^{11}$ um diferencial dessa revista é a presença de pessoas diretamente ligadas à comunidade científica, como físicos, biólogos, químicos, médicos, engenheiros 
etc., no seu corpo editorial. Após 6 anos de preparo e discussão, em julho de 1982, durante a $34^{\mathrm{a}}$ Reunião Anual da SBPC, foi lançado o primeiro número da revista Ciência Hoje. O objetivo de seus editores era "estabelecer um canal de comunicação entre a comunidade científica e o grande público; e promover o debate público em torno de questões como cidadania, educação e participação universitária, possibilitando, assim, a democratização da ciência". ${ }^{12}$

Segundo Ivanissevich, ${ }^{12}$ como primeira revista de divulgação científica do país, fazia-se necessário superar um obstáculo decisivo do momento: substituir a linguagem especializada dos artigos científicos por textos de maior simplicidade e clareza, sem perda do rigor científico. De acordo com a autora, as iniciativas isoladas de popularização da ciência da época - como programas de rádio, entrevistas na televisão, boletins informativos de sociedades científicas etc. - muito contribuíram para estimular o debate e preparar o terreno para um projeto de divulgação científica. No período entre seu lançamento e o ano de 2002, mais de dois mil cientistas brasileiros e dezenas de outros trabalhando no exterior escreveram artigos para a revista. Cerca de 850 pesquisadores foram consultados para avaliar os artigos e mais de 70 jornalistas colaboraram com a revista. ${ }^{12}$

Os textos da revista estão divididos em dois tipos: artigos e seções. Os artigos devem apresentar uma abordagem ampla e aprofundada sobre temas de grande abrangência e interesse geral, enquanto as seções focalizam assuntos específicos. Os artigos devem conter abertura (resumo), sugestões para leitura, título, retranca (área do conhecimento: física, biologia, antropologia etc.) e ilustrações devidamente legendadas e com crédito. A maioria das seções só exige título, retranca e ilustrações. A revista apresenta as seguintes seções: Mundo de Ciência, Em Dia, Opinião, Polêmica, Memória, Resenha e Ensaio. ${ }^{13}$

Vale salientar que centramos nossa investigação nos artigos (reportagens de capa), por oferecerem matérias mais ricas em detalhes e informações diferenciadas, proporcionando uma maior variedade de possibilidades de uso didático.

\section{INSTRUMENTOS DE ANÁLISE DOS TDCS}

\section{Conteúdo e forma dos TDCs}

Os instrumentos de análise adotados para esta pesquisa foram adaptados dos trabalhos de Salém e Kawamura ${ }^{9}$ e Ribeiro e Kawamura. ${ }^{10}$ No primeiro trabalho foi feita uma caracterização e análise das perguntas de leitores de publicações de divulgação científica, procurando estabelecer elementos que orientassem sua utilização no ensino de física. Ribeiro e Kawamura ${ }^{10}$ desenvolveram um instrumento de análise, baseado em categorias referentes ao conteúdo e à forma, de modo a caracterizar TDCs segundo os diferentes veículos de comunicação em que são publicados. Dessa forma, o quadro de categorias para a caracterização e análise dos artigos foi organizado dentro de duas perspectivas principais: conteúdo e forma. Na Figura 1 está ilustrado o esquema referente à análise dos artigos segundo Kawamura e colaboradores. ${ }^{9,10}$

No que diz respeito ao conteúdo, realizamos uma análise geral na qual buscamos identificar os conteúdos principais dos artigos analisados e, dessa forma, os classificamos em três subcategorias: Química, Fronteiras e Temas Transversais. A primeira diz respeito aos conteúdos considerados de acordo com a estruturação formal do conhecimento químico, normalmente reproduzida no ensino escolar. A subcategoria Fronteiras abarca conteúdos não tradicionalmente incluídos no ensino formal da química, mas a ela relacionados, como a física, por exemplo. Os conteúdos relacionados aos Temas Transversais são aqueles tais como estão

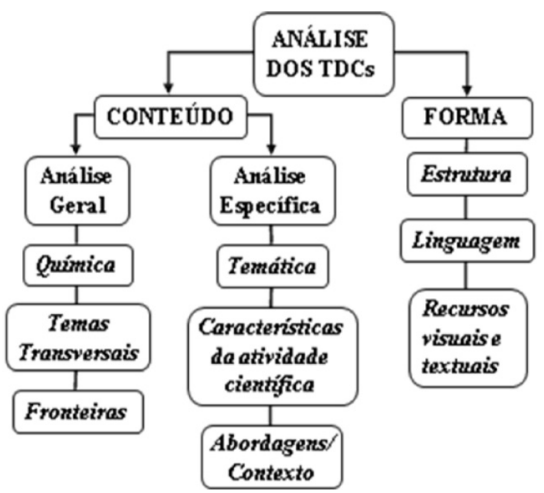

Figura 1. Esquema adotado para a análise dos TDCs com base nos instrumentos de análise propostos por Kawamura e colaboradores ${ }^{9,10}$

explicitados nos Parâmetros Curriculares Nacionais (PCNs) e são assim adjetivados por não pertencerem a nenhuma disciplina específica, mas atravessarem todas elas como se a todas fossem pertinentes. Em outras palavras, são temas que abordam valores referentes à cidadania. ${ }^{5}$

Cada um dos conteúdos gerais é, em seguida, classificado segundo temas específicos: temática, características da atividade científica e abordagens e contexto. Na subcategoria temática são investigados os enfoques dados ao conteúdo tratado no artigo. A subcategoria características da atividade científica engloba aspectos relativos à práxis científica, tanto do ponto de vista dos procedimentos (elaboração e adequação de modelos, formas pelas quais são feitas as tomadas de dados, processos de análise dos dados, interpretação dos resultados etc.) quanto da ciência como instituição (controvérsias científicas, diversidade de ideias, relações entre os processos da ciência e seus produtos etc.). Considera-se também pertencente a essa subcategoria os aspectos inerentes à natureza da ciência, como a quebra de paradigmas, características pessoais dos cientistas, entre outros. A subcategoria abordagens e contexto indica a forma pela qual o texto é contextualizado, ou seja, inserido em um contexto social, político e/ou econômico.

Vale destacar que foi feita uma adaptação no instrumento originalmente proposto pelas autoras,,${ }^{9,10}$ o qual apresentava as subcategorias "procedimentos internos da ciência" e "funcionamento institucional da ciência", que foram por nós associadas à subcategoria que denominamos de "características da atividade científica". Essa adaptação se fez necessária porque, ao fazermos uma pré-análise dos TDCs, encontramos exemplos que estavam relacionados a aspectos da prática científica que não se encaixavam em nenhuma delas.

A dimensão forma compreende a estrutura do texto, a linguagem e os recursos visuais e textuais utilizados. Na subcategoria estrutura observa-se como os textos estão construídos e a maneira como as informações estão encadeadas e distribuídas. A subcategoria linguagens diz respeito à clareza dos textos, formas com as quais os autores fazem uso de termos e conceitos científicos, uso de metáforas, analogias, gêneros discursivos empregados etc. Nos recursos visuais e textuais procura-se identificar a distribuição espacial das informações, uso de ilustrações, fotografias, boxes, notas de margens etc.

\section{RESULTADOS E DISCUSSÃO}

\section{Distribuição dos TDCs na revista Ciência Hoje}

Como ponto de partida, foi feita uma leitura de todos os números publicados da revista em pauta entre os anos de 2004 e 2009. A partir de tal leitura, foram identificadas 298 TDCs relacionados direta ou indiretamente à química. Conforme ilustra a Figura 2, estes estão 


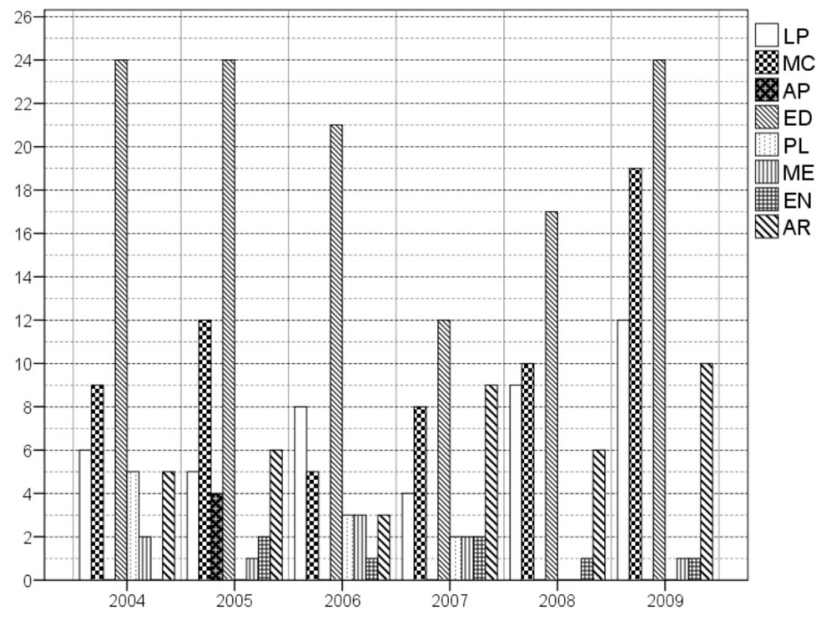

Figura 2. Número de TDCs da revista Ciência Hoje separados por seção (O Leitor Pergunta (LP), Mundo de Ciência (MC), A Propósito (AP), Em Dia (ED), Primeira Linha (PL), Memória (ME), Ensaio (EN) e na forma de artigos da revista $(A R))$, para cada ano pesquisado

distribuídos nas seções O Leitor Pergunta (LP), Mundo de Ciência (MC), A Propósito (AP), Em Dia (ED), Primeira Linha (PL), Memória (ME), Ensaio (EN) e na forma de artigos da revista (AR).

Como os TDCs na forma de artigos são os objetos de estudo deste trabalho, apresentamos na Tabela 1 os títulos dos textos analisados, assim como as áreas a que se relacionam e o mês/ano de publicação. Ressaltamos que tais textos serão referidos ao longo do manuscrito por meio do número ao qual estão relacionados na Tabela 1 .

Na Figura 3 encontra-se apresentada a relação entre o número de TDCs na forma de artigos e os TDC das demais seções da revista para cada ano pesquisado.

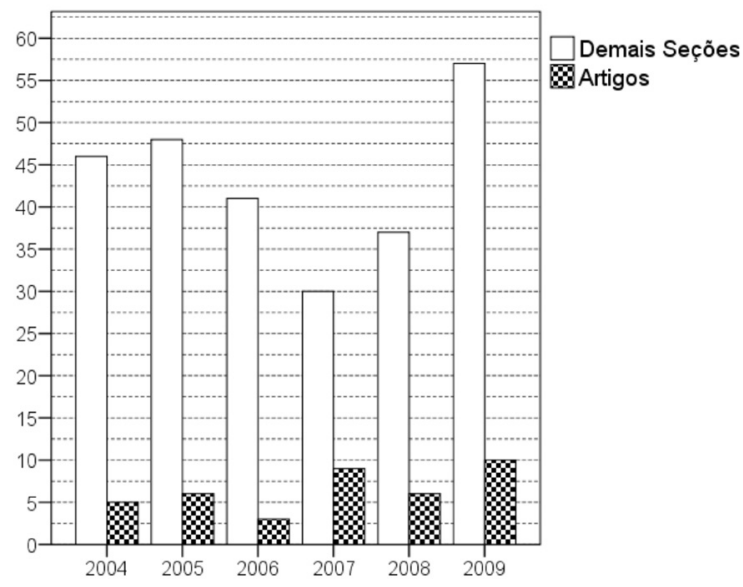

Figura 3. Número de artigos da revista Ciência Hoje em relação às demais seções, ao longo dos anos pesquisados

Cabe destacar que os textos foram analisados nas duas perspectivas ilustradas na Figura 1 e as categorias de análise se aplicam a todos. No entanto, devido às limitações de espaço típicas da Revista Química Nova, apresentamos a análise de apenas um deles na perspectiva de todas as categorias e subcategorias e a análise dos 39 textos (Tabela 1) apenas para a perspectiva conteúdo, subcategoria análise geral. Com o intuito de disponibilizar ao leitor uma maior quantidade de informações sobre o uso de todas as categorias, apresentamos como material suplementar a análise de mais dois artigos considerando todas elas.

\section{Análise dos artigos: conteúdos gerais}

Na Figura 4 os 39 artigos investigados estão distribuídos de acordo com as subcategorias relacionadas ao conteúdo - Química, Fronteiras e Temas Transversais -, conforme explicitado anteriormente. Cabe salientar que todos os artigos apresentam retranca indicando a área de conhecimento a qual estão relacionados. Dessa forma, essa categorização foi feita a partir da área indicada na própria revista. Ou seja, os artigos nos quais a área "Química" estava indicada na retranca representam a primeira subcategoria e os demais foram alocados nas subcategorias Fronteiras - como o artigo cuja retranca indica a área "Fitoquímica" (2), por exemplo - e Temas Transversais, como o artigo que tem a área "Ecotoxicologia" (28) apresentada na retranca. Vale lembrar que essa classificação obedeceu aos critérios descritos anteriormente para essas duas subcategorias.

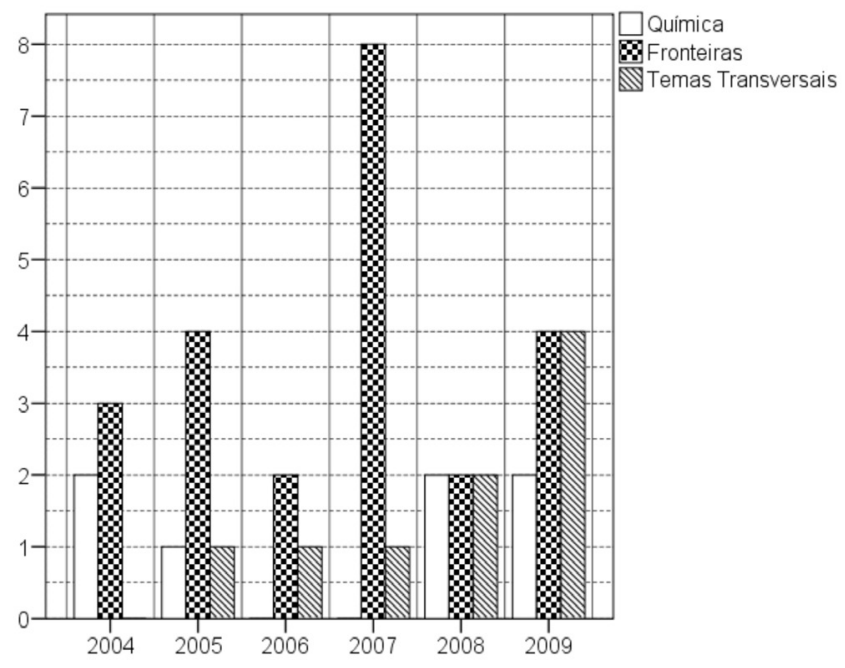

Figura 4. Número de artigos da revista Ciência Hoje para cada subcategoria relacionada a conteúdo, ao longo dos anos pesquisados

É possível perceber pela Figura 4 que, ao longo dos anos estudados, 7 TDCs têm a Química como a área indicada (3, 5, 11, 25, 26, 31, 32). Os demais TDCs, 32 no total, estão incluídos em diversas áreas, as quais têm ligação com a química. A Figura 5 ilustra o total de áreas indicadas incluídas na subcategoria Fronteiras (23 artigos). Um exemplo de artigo classificado nessa subcategoria diz respeito a uma publicação de outubro de 2005, intitulado "A energia nuclear e seus usos na sociedade", que tem a "Física" como área indicada na retranca (9). Embora esse artigo se refira diretamente à física, verificamos a ocorrência de diversos assuntos estreitamente ligados à química, como o conceito de isótopos, por exemplo.

Os 9 artigos que contemplam a subcategoria Temas Transversais estão divididos igualmente nas seguintes áreas: Ecotoxicologia (28), Limnologia (22), Nanociência e Nanotecnologia (8), Política Energética (29), Tecnologia Energética (13), Ecologia (33), Geologia Ambiental (35), Física Médica (37) e Farmacologia (39).

Embora aparentemente algumas dessas áreas não tenham relação com os Temas Transversais, foi feita uma leitura criteriosa dos textos, o que permitiu classificá-los nessa subcategoria. Como, por exemplo, o artigo "A qualidade do sedimento: contaminação por metais pode ser ameaça aos seres vivos", publicação de novembro de 2007 e cuja retranca indica a área "Limnologia" (22), o qual trata especificamente da qualidade de sedimentos acumulados no fundo dos corpos d'água e dos perigos ao meio ambiente por conta da sua contaminação por metais pesados. Assim, consideramos que o conteúdo do referido artigo contempla os Temas Transversais por apresentar forte apelo ao meio ambiente. 
Tabela 1. Descrição dos artigos identificados no trabalho de seleção dos TDCs da revista Ciência Hoje relacionados à química, no período de 2004 a 2009

\begin{tabular}{|c|c|c|}
\hline No. & Artigo & Área \\
\hline 1 & Serotonina: a trajetória evolutiva de uma molécula de ampla ação trófica e neurológica (Março/2004) & Bioquímica \\
\hline 2 & Valerianas brasileiras: potencial terapêutico de espécies do Sul do país (Maio/2004) & Fitoquímica \\
\hline 3 & Eletricidade estática: onde ficam as cargas? (Setembro/2004) & Química \\
\hline 4 & Luciferases: as enzimas da luz (Outubro/2004) & Bioquímica \\
\hline 5 & Catalisadores: em busca de estruturas de superfície (Dezembro/2004) & Química \\
\hline 6 & Mecânica quântica: uma nova forma de ver o mundo (Março/2005) & Física \\
\hline 7 & Os alquimistas (virtuais) estão chegando (Maio/2005) & Física de Materiais \\
\hline 8 & Nanociência e nanotecnologia: o gigantesco e promissor mundo do muito pequeno (Julho/2005) & Nanociência e Nanotecnologia \\
\hline 9 & A energia nuclear e seus usos na sociedade (Outubro/2005) & Física \\
\hline 10 & A RMN e suas aplicações (Novembro/2005) & Física \\
\hline 11 & Os cristais e a origem da vida: a seleção química de aminoácidos na Terra primitiva (Dezembro/2005) & Química \\
\hline 12 & Motores moleculares (Setembro/2006) & Bioquímica \\
\hline 13 & Energia verde (Novembro/2006) & Tecnologia Energética \\
\hline 14 & Carboidratos: de adoçantes a medicamentos (Dezembro/2006) & Bioquímica \\
\hline 15 & Paisagens subterrâneas do Brasil (Março/2007) & Espeleologia \\
\hline 16 & A descoberta racional de fármacos (Março/2007) & Química Farmacêutica \\
\hline 17 & RNA de interferência: nova ferramenta para o estudo da ação da insulina em adipócitos (Abril/2007) & Bioquímica \\
\hline 18 & A química do cosmo: segredo revelado pelos meteoritos (Maio/2007) & Cosmoquímica \\
\hline 19 & Pereirina: o primeiro alcalóide isolado no Brasil (Agosto/2007) & Fitoquímica \\
\hline 20 & A rica polêmica sobre o urânio empobrecido (Setembro/2007) & Química Biológica \\
\hline 21 & Enzimas: poderosas ferramentas na indústria (Outubro/2007) & Biotecnologia \\
\hline 22 & A qualidade do sedimento: contaminação por metais pode ser ameaça a seres vivos (Novembro/2007) & Limnologia \\
\hline 23 & As damas de companhia das proteínas (Dezembro/2007) & Bioquímica \\
\hline 24 & Um novo estado da matéria (Março/ 2008) & Física \\
\hline 25 & A química na padaria: o açúcar nos pães dietéticos (Abril/2008) & Química \\
\hline 26 & $\begin{array}{c}\text { De óleos e ungüientos aos fármacos modernos: o desenvolvimento de medicamentos e a evolução da química } \\
\text { medicinal (Junho/2008) }\end{array}$ & Química \\
\hline 27 & Os combustíveis do exercício físico (Agosto/2008) & Bioquímica \\
\hline 28 & $\begin{array}{l}\text { Solução biode(sa)gradável: componente de detergentes e cosméticos pode dar origem a substâncias tóxicas } \\
\text { (Novembro/2008) }\end{array}$ & Ecotoxicologia \\
\hline 29 & Angra 3: uma decisão polêmica (Novembro/2008) & Política Energética \\
\hline 30 & Rabiscando a eletrônica com o grafeno (Março/2009) & Física \\
\hline 31 & Atratores luminosos: poluição na costa brasileira (Março/2009) & Química \\
\hline 32 & O estado líquido cristalino (Maio/2009) & Química \\
\hline 33 & $\begin{array}{l}\text { A Amazônia e o aquecimento global: os desafios para quantificar as emissões de gases de efeito estufa pelo } \\
\text { desmatamento (Julho/2009) }\end{array}$ & Ecologia \\
\hline 34 & A física nuclear nas artes e na arqueologia (Agosto/2009) & Arqueometria \\
\hline 35 & Cemitérios: fontes potenciais de contaminação (Setembro/2009) & Geologia Ambiental \\
\hline 36 & Supercondutividade de alta temperatura crítica (Setembro/2009) & Física \\
\hline 37 & Aterosclerose: nova técnica avalia risco e ajuda a prevenir a doença (Novembro/2009) & Física Médica \\
\hline 38 & Doença de Chagas: a invasão silenciosa do parasito (Dezembro/2009) & Bioquímica \\
\hline 39 & Ginkgo biloba: o chá das folhas é seguro? (Dezembro/2009) & Farmacologia \\
\hline
\end{tabular}

Conforme mencionamos anteriormente, tendo em vista a impossibilidade de apresentação detalhada neste manuscrito da análise relacionada aos conteúdos específicos e forma para todos os artigos, selecionamos um deles e apresentamos um exemplo de como a análise foi realizada. Acreditamos que as apreciações dessa análise, juntamente com as indicações provenientes da análise geral, poderão auxiliar os professores no estabelecimento de critérios para seleção e uso de TDCs em sala de aula.

\section{Análise do artigo "Eletricidade estática - onde ficam as cargas?": conteúdos específicos e forma}

O texto selecionado para a análise intitulado "Eletricidade es- 


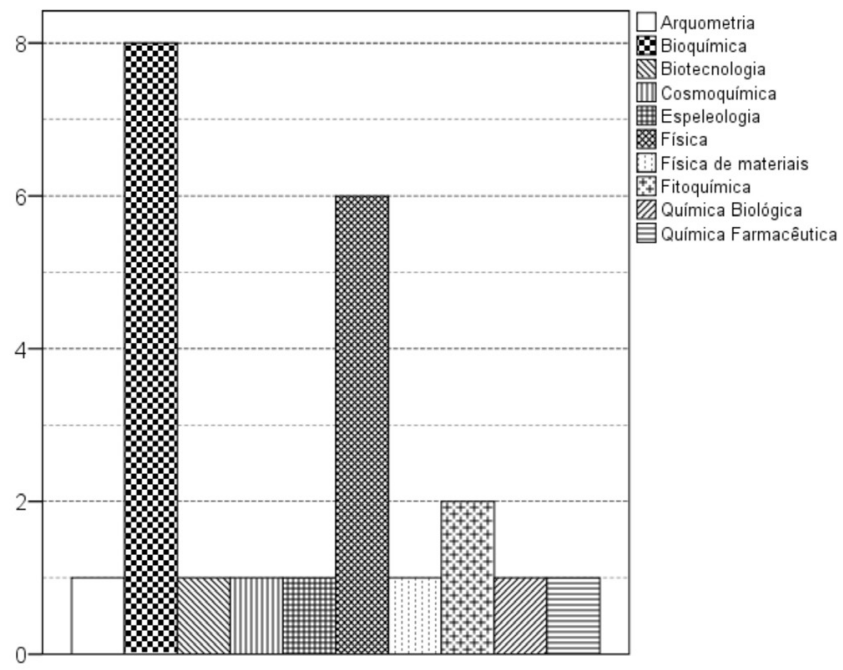

Figura 5. Áreas da subcategoria Fronteiras identificadas nos artigos da revista Ciência Hoje, no total dos anos pesquisados

tática: Onde ficam as cargas?" (3) é assinado por F. Galembeck, A. F. Ramos e R. F. Gouveia, do Instituto de Química da Universidade Estadual de Campinas e foi publicado em setembro de 2004. ${ }^{14}$

Apresentamos inicialmente a análise dos conteúdos específicos, ou seja, a identificação da temática, características da atividade científica e abordagens e contextos presentes nos artigos. Em seguida, são evidenciados e discutidos os aspectos característicos encontrados nos textos no que diz respeito à forma, especialmente sua estrutura, linguagem e recursos visuais e textuais.

\section{Temática}

O texto tem como temática a problemática que envolve a ocorrência dos fenômenos eletrostáticos em alguns materiais. Segundo os autores, o fato de ainda não haver explicação para as causas desses fenômenos acarreta vários problemas tecnológicos, portanto, colocam a necessidade de buscar respostas para essa questão e contribuir para avanços na área.

$\mathrm{O}$ artigo é iniciado com uma breve definição sobre os fenômenos eletrostáticos, passando ao segundo tópico ("Elétrons, íons ou ambos?"), o qual dá prosseguimento às conceituações e definições de termos relacionados ao tema. O segundo tópico ("Ignorância problemática") coloca o problema principal do artigo: o fato de não serem conhecidas as causas da eletricidade estática em diversos materiais. Entre o terceiro e o penúltimo tópicos ("Acidentes e desastres", "Questão mais desafiadora", "Kelvin mais força atômica", "Interior e casca", "O que já aprendemos" e "Formulando hipóteses", respectivamente) temos descrições das teorias relacionadas aos avanços já feitos na área e as hipóteses mais prováveis de resolução do problema. O último tópico apresenta uma aplicação dos estudos desenvolvidos.

\section{Características da atividade científica}

São feitas várias referências às características da atividade científica. Inicialmente são destacados os relatos dos autores sobre as pesquisas desenvolvidas por eles, nos quais foram observadas a formulação de hipóteses [1], descrição de metodologias científicas [2], combinação de diferentes métodos [3], interpretação de resultados [4] e conclusões das pesquisas [5]:

[1] "Assim, para levar o trabalho adiante, precisamos formular novas hipóteses de trabalho".

[2] "Em nosso laboratório, os mapas de potenciais elétricos são obtidos da seguinte forma: a amostra é colocada sobre uma placa de alumínio que está ligada à terra (...)".

[3] "Esse resultado concorda muito bem com o que é obtido no mapa de potenciais elétricos das mesmas partículas, usando-se a microscopia de varredura de potenciais elétricos, ou seja, a combinação do método de Kelvin com um microscópio de força atômica".

[4] "Esse resultado também mostra que, se alguns íons potássio forem retirados por atrito de uma região da superfície, esta ficará com excesso de íons sulfato e, assim, o plástico ficará negativo".

[5] "Graças a isso, aprendemos que não há uma solução geral para a natureza e identidade dos portadores de cargas nos plásticos: ela deve ser descoberta experimentalmente em cada material (...)”.

Diversos trechos também revelam aspectos característicos da atividade científica, de certo modo implícitos ou pouco conhecidos pelo público em geral, como as limitações dos cientistas e as dificuldades por eles enfrentadas [6, 7], a cooperação entre diferentes campos de conhecimento [8] e a obtenção de patentes [9]:

[6] "Não sabemos quais são as substâncias ou partículas responsáveis pela eletricidade de muitas substâncias (...)".

[7] "Essa nossa ignorância cria vários problemas tecnológicos (...)". [8] "Essa hipótese baseia-se em algumas informações que vêm de outras áreas de pesquisa".

[9] "Essa aplicação das cargas negativas do látex é o assunto de uma patente da Unicamp e está sendo explorada em um projeto da empresa (...)".

Foram também identificados alguns trechos que se referem às controvérsias científicas [10,11], à necessidade de reconhecimento das pesquisas científicas perante a comunidade científica [12] e à importância da aplicabilidade dessas pesquisas [13]:

[10] “(...) não há qualquer consenso quanto à natureza dos portadores de cargas em dielétricos e esta permanece como um grande desafio ao conhecimento científico atual (...)".

[11] "Afirmações de vários especialistas mostram a falta de concordância sobre uma questão crucial (...)".

[12] "Além disso, muitos autores já reconhecem que as interações eletrostáticas são decisivas na escala nanométrica (...)".

[13] "É muito importante procurarmos aplicar toda a ciência que vamos adquirindo através da pesquisa. Os projetos executados no laboratório dos autores deste artigo, na Unicamp, já geraram pelo menos uma aplicação importante (...)".

A partir dos exemplos apresentados pode-se observar a forma como o TDC revela aspectos implícitos da natureza da ciência, o que corrobora sugestões reportadas na literatura sobre as suas potencialidades no auxílio a uma compreensão mais adequada da ciência. ${ }^{1,2}$

\section{Abordagens e contexto}

Com relação à subcategoria abordagens e contexto, considera-se que o texto mescla questões de ordem conceitual com questões de ordem cotidiana, pois, ao mesmo tempo que trata de conceituações, definições de termos e descrição de métodos de investigação da área, como em [14], também apresenta a forma como esse assunto está inserido no dia-a-dia do leitor [15]:

[14] "Há novas e importantes perspectivas de desenvolvimentos tecnológicos baseados em eletrostática. Recentemente, foi dado um passo importante na construção de um motor eletrostático para acionamento de memórias de computador".

[15] "Essas novidades tecnológicas estão associadas a uma intensa e 
contínua atividade de controle de descargas eletrostáticas, especialmente na introdução de equipamentos de proteção física de pessoas, construções e máquinas".

\section{Estrutura}

Com relação à estrutura, o texto apresenta-se de forma bastante fragmentada, com a presença de dez tópicos relativamente pequenos que dividem espaço com quatro boxes. Dessa forma, é possível ao interlocutor fazer sua leitura por partes independentes. Pela quantidade considerável de tópicos podemos sugerir também que os autores não têm a finalidade de apresentar os assuntos com profundidade, mas mostrar ao leitor um apanhado geral do assunto.

\section{Recursos visuais e textuais}

No que diz respeito aos recursos visuais e textuais, o texto está escrito em 8 páginas e seu título também ocupa página dupla, destacado em letras grandes. A expressão "Onde ficam as cargas?" bem exemplifica a proposta do texto. Duas fotos dividem o espaço ao fundo da página dupla: de um lado um gerador de van de Graaf, de outro o conhecido experimento de eletrostática do pente eletrizado atraindo pequenos pedaços de papel. É interessante notar o contraste de imagens colocadas, uma vez que o primeiro é típico do discurso científico e o outro do discurso cotidiano.

Nas retrancas a área indicada é "Química" e a abertura do texto aparece na lateral esquerda da primeira página, com a referência autoral logo abaixo. Na segunda página o texto é iniciado, com a seguinte frase em destaque: "Os fenômenos eletrostáticos". O texto apresenta nove intertítulos que anunciam os tópicos do texto já descritos nesta análise.

$\mathrm{O}$ texto apresenta quatro boxes relativamente curtos. O primeiro ("De Tales a Bohr") aborda os principais marcos históricos dos estudos relacionados à eletrização de objetos. O segundo box ("Uma questão crucial") apresenta um diálogo retirado de um artigo científico internacional, o qual destaca as controvérsias diante da ocorrência de cargas nos materiais. O terceiro box ("Sobre métodos e equações") aborda questões relativas a dificuldades teóricas e experimentais para a compreensão dos fenômenos eletrostáticos. Para tanto, nesse box os autores explicam porque alguns métodos e equações são limitados. No quarto box ("Simulação computacional") os autores descrevem como a simulação computacional pode auxiliar nas investigações a respeito do assunto.

São encontradas apenas 5 figuras. Na primeira são colocadas três fotos que ilustram como são medidos potenciais elétricos de isolantes. A segunda figura apresentada mostra imagens obtidas de microscópios de força atômica de um filme de látex. A terceira figura apresenta dois mapas de distribuição de cargas e um mapa de potenciais elétricos. A quarta figura também apresenta mapas de potenciais elétricos. A quinta figura mostra a foto de plásticos colorizados, aplicação gerada pelos estudos desenvolvidos no grupo de pesquisa dos cientistas.

\section{Linguagem}

O texto em pauta apresenta linguagem moderadamente acessível. Apresenta vários termos técnicos e científicos, no entanto, a densidade desses termos é amenizada com a presença de vários procedimentos explicativos e aproximações com o cotidiano. O recurso da definição é usado com frequência no texto, conforme ilustram os exemplos a seguir:

[16] "Atualmente, explicamos fenômenos elétricos como sendo a consequência (a) da existência de cargas elétricas e de seu movimento, e (b) do desequilíbrio entre as quantidades de cargas positivas e negativas nos diferentes meios materiais".
[17] “(...) e nos semicondutores (materiais classificados entre os condutores e os isolantes)".

[18] “(...) uma lacuna em um dielétrico molecular é um íon molecular, ou seja, um átomo ou uma molécula dotados de carga elétrica positiva".

A aproximação foi uma das formas de definição mais usadas pelos autores dos textos, na qual o enunciador procura garantir a compreensibilidade do destinatário, buscando elementos que guardam equivalência conceitual com o objeto científico a ser explicado. Acredita-se que este seja um recurso que diminui a distância do leitor com o texto, uma vez que ele percebe a relação do que está escrito com sua vivência diária:

[19] "Entretanto, não sabemos ainda quais são os portadores de cargas em polímeros comuns, como o polietileno e o polipropileno, que são os plásticos mais comuns, muito usados em utensílios de todo o tipo e em embalagens".

[20] "Ainda não é possível, por exemplo, determinar qual é a distribuição de potenciais elétricos através do volume ou da superfície de qualquer objeto feito de um material não condutor, como plástico, vidro, cerâmica, borracha etc."

Essa tentativa de aproximação do leitor com o texto também se deu por meio do uso de outras estratégias discursivas, como o uso de aspas [21], de tessitura lexical (o tom de leveza que é dado a algumas palavras) [22] e alguns casos de interlocução direta com o leitor [23].

[21] “(...) comumente, se diz que o equipamento tem um 'fio terra'”. [22] "Já nas regiões e estações úmidas, a eletrostática se faz sentir pelas formidáveis tempestades de relâmpagos (...)".

[23] "São elétrons, são íons ou ambos? Se são íons, qual é a sua natureza química (ver 'Uma questão crucial')?”

Tais estratégias exemplificam os traços de laicidade presentes no texto. O uso de aspas pode ser utilizado com diversos objetivos. No texto em questão o aspeamento foi usado principalmente nas comparações, com a função de marcar a estranheza e o distanciamento relativo ao emprego dessas palavras/expressões, que representam outras situações, e dar a elas conotação metafórica. ${ }^{15}$ É importante deixar claro que o aspeamento pode ocorrer tanto em um termo técnico-científico, como em palavras coloquiais. De fato, termos científicos marcados com aspas também foram observados.

No que diz respeito à ocorrência de tessitura lexical em alguns pontos do texto, percebe-se que à medida que o narrador enuncia os acontecimentos, se constitui ativo, manifestando suas impressões. Da mesma forma o narrador constitui um interlocutor também participante, chamado a compartilhar das mesmas emoções. Ribeiro e Kawamura ${ }^{10}$ também identificaram essa característica em sua análise e perceberam que ela ocorre tanto através da aproximação temporal entre autor-leitor, como por meio de questionamentos diretos ao leitor (interlocução direta) ao longo do texto.

Do mesmo modo, os segmentos que estabelecem a interlocução direta com o leitor constituem uma forma de buscar a participação ativa do leitor, aproximando-o do processo de produção do texto e fazendo-o compartilhar das mesmas apreciações que o autor experimenta ao tomar conhecimento do objeto de sua fala. ${ }^{15}$

\section{CONSIDERAÇÕES FINAIS}

Neste manuscrito foram apresentados resultados de um trabalho de seleção e análise de TDCs relacionados à química, publicados na revista Ciência Hoje, no intervalo de 2004 a 2009. Foi constatado, 
inicialmente, que a quantidade identificada de artigos relacionados à química - assim como a variedade de conteúdos presentes - constitui um acervo razoável de TDCs disponível para uso de professores de química de diferentes níveis de ensino.

A diversidade de abordagens apresentada nos artigos indica as possibilidades variadas de enfoques que os professores podem imprimir em suas aulas. Do mesmo modo, a grande ocorrência de artigos concernentes às Fronteiras da química e aos Temas Transversais (cerca de $82 \%$ ) sinaliza as contribuições que os TDCs podem oferecer a um ensino de química que prima pela interdisciplinaridade e contextualização. Ademais, esses resultados evidenciam a abrangência e as possibilidades ampliadas de aprendizagem que representam.

Concluiu-se também que a análise empreendida mostrou a adequação do instrumento de investigação proposto nos trabalhos orientados por Kawamura e colaboradores, ${ }^{9,10}$ uma vez que permitiu observar características nos textos de maneira criteriosa.

Podemos sugerir que a análise dos TDCs na perspectiva do conteúdo (análise geral) oferece subsídios para o professor na escolha do tipo de artigo que deseja utilizar, especialmente com relação aos assuntos que pretende abordar, enquanto que a análise na perspectiva de conteúdo (análise específica) e forma permite ao professor o reconhecimento de vários aspectos que podem ser explorados na sala de aula.

Por fim, acreditamos que a análise apresentada contribui para fornecer um quadro mais preciso a respeito dos recursos que os TDCs publicados na revista Ciência Hoje oferecem para o ensino de química, constituindo um material conveniente para os professores que optarem por diversificar suas aulas e promover o desenvolvimento de visões críticas sobre assuntos científicos.

\section{MATERIAL SUPLEMENTAR}

O material contendo a análise dos textos 11 e 22 (Tabela 1), na perspectiva de todas as categorias do instrumento de análise empregado neste artigo, encontra-se disponível gratuitamente em http:// quimicanova.sbq.org.br, na forma de arquivo PDF.

\section{AGRADECIMENTOS}

À Fundação de Amparo à Pesquisa do Estado de São Paulo - FAPESP (Processo 2008/10577-5) e ao Conselho Nacional de Pesquisa e Desenvolvimento - CNPq (Processo 302455/2009-4) pelo auxílio financeiro.

\section{REFERÊNCIAS}

1. Terrazzan, E. A.; Gabana, M.; Atas do III Encontro Nacional de Pesquisa em Educação em Ciências, Atibaia, Brasil, 2003.

2. Martins, I.; Nascimento, T. G.; Abreu, T. B.; Investigações em Ensino de Ciências 2004, 9, 95.

3. Silva, H. C.; Almeida, M. J. P. M.; Revista Electrónica de Enseñanza de las Ciencias 2005, 4, 155.

4. Strack, R.; Loguercio, R.; Del Pino, J. C.; Ciência e Educação 2009, 15, 425.

5. Brasil.; Parâmetros Curriculares Nacionais: Ciências Naturais, 1997. http://portal.mec.gov.br/seb/arquivos/pdf/livro04.pdf, acessada em Maio 2010.

6. Gomes, M. C.; Da Poian, A. T.; Goldbach, T.; Atas do VI Encontro Nacional de Pesquisa em Educação em Ciências, Florianópolis, Brasil, 2007.

7. Pereira, A. G.; Duarte, A. B.; Terrazzan, E. A.; Atas do VII Encontro Nacional de Pesquisa em Educação em Ciências, Florianópolis, Brasil, 2009.

8. Goldbach, T.; El-Hani, C. N.; Alexandria: Revista de Educação em Ciência e Tecnologia 2008, 1, 153.

9. Salém, S.; Kawamura, M. R. D.; Atas do II Encontro Nacional de Pesquisa em Educação em Ciências, Valinhos, Brasil, 2001.

10. Ribeiro, R. A.; Kawamura, M. R. D.; Atas do V Encontro Nacional de Pesquisa em Educação em Ciências, Bauru, Brasil, 2005.

11. Dias, R. H. A.; Dissertação de Mestrado, Universidade Estadual de Campinas, Brasil, 2009.

12. Ivanissevich, A.; Ciência Hoje 2002, 31, 24.

13. http://cienciahoje.uol.com.br/revista-ch/instrucoes-para-autores, acessada em Maio 2010 e Novembro 2010.

14. Galembeck, F.; Ramos, A. F.; Gouveia, R. F.; Ciência Hoje 2004, 35, 32.

15. Zamboni, L. M. S.; Cientistas, jornalistas e a divulgação científica: subjetividade e heterogeneidade no discurso da divulgação científica, Autores Associados: Campinas, 2001. 
Luciana Nobre de Abreu Ferreira

Universidade Federal de São Carlos, Rod. Washington Luís, km 235, 13565-905 São Carlos - SP, Brasil

Salete Linhares Queiroz*

Instituto de Química de São Carlos, Universidade de São Paulo, CP 780, 13560-970 São Carlos - SP, Brasil

\section{MATERIAL SUPLEMENTAR}

O material suplementar traz as análises de dois textos, realizadas nos mesmos moldes utilizados na análise descrita no manuscrito para o texto "Eletricidade estática - onde ficam as cargas?", com o intuito de apresentar mais exemplos de verificação das características dos TDCs, evidenciar suas possibilidades didáticas e reforçar as conclusões apresentadas.

\section{ANÁLISE DO ARTIGO INDICADO PELO NÚMERO 11 NA TABELA 1:}

Os cristais e a origem da vida: a seleção quiral de aminoácidos na Terra primitiva

O texto intitulado "Os cristais e a origem da vida: a seleção quiral de aminoácidos na Terra primitiva" é assinado por D. A. M. Zaia e C. T. B. V. Zaia, da Universidade Estadual de Londrina.

Apresentamos inicialmente a análise dos conteúdos específicos (temática, características da atividade científica e abordagens $e$ contextos) presentes no artigo e, em seguida, são evidenciados e discutidos os aspectos característicos concernentes à forma (estrutura, linguagem e recursos visuais e textuais).

\section{Temática}

O texto tem como temática a quiralidade dos aminoácidos, especialmente a busca por explicações sobre a 'preferência' dos organismos vivos em seu metabolismo por apenas uma das formas pelas quais os aminoácidos são apresentados. Portanto, os autores relatam no TDC estudos que apontam minerais como fortes candidatos ao papel de agentes selecionadores de aminoácidos na Terra primitiva.

Na introdução do artigo os autores trazem uma contextualização a respeito da presença de aminoácidos, peptídeos e proteínas na grande maioria das reações químicas que acontecem nas células e seres vivos. Assim, neste tópico são apresentados alguns dos principais papéis desempenhados no metabolismo dos seres vivos por essas substâncias, bem como sua constituição química. No segundo tópico ("L-aminoácidos e D-aminoácidos") os autores fazem uma descrição da propriedade 'quiralidade' dos aminoácidos. No tópico "A 'preferência' dos seres vivos" os autores trazem uma discussão sobre a predominância de aminoácidos na forma de isômeros L e apontam possíveis justificativas para tal.

O terceiro tópico ("Seleção quiral por minerais"), como o próprio título indica, apresenta argumentos que defendem a contribuição decisiva dos minerais na seleção de L-aminoácidos. O último tópico ("Algumas questões em aberto") coloca que os estudos realizados até então são inconclusivos por meio da apresentação dos pontos falhos desses estudos.

\footnotetext{
*e-mail: salete@iqsc.usp.br
}

Características da atividade científica

Aspectos pertencentes à dimensão características da atividade científica foram observados. Inicialmente destacamos os exemplos referentes a características explícitas da atividade científica, como a descrição de metodologias/técnicas experimentais $[1,2]$ e resultados de observações $[3,4]$. Estas foram também identificadas, contudo, em pequenas quantidades e sem revelar maiores detalhes a respeito, conforme exemplificamos nos trechos a seguir:

[1] "Esse desvio é detectado por equipamentos ópticos, que permitem detectar o ângulo de rotação do plano”.

[2] “Após algum tempo nessa solução, os cristais foram retirados e cada face foi cuidadosamente levada com uma solução de ácido, para retirar o material adsorvido".

[3] "Foi observado (...) que a polimerização de misturas racêmicas de aminoácidos (...) em solução aquosa, promovida por um agente condensante (...) formou mais peptídeos (...) do que o esperado".

[4] "Foi observado que, na maioria das faces, a relação D/L era quase igual a 1, indicando que foram adsorvidas quantidades iguais das duas formas ( $D$ e L) do aminoácido”.

A formulação de hipóteses foi uma característica evidente no TDC em questão, uma vez que as pesquisas relacionadas ao assunto ainda não são conclusivas e, por esse motivo, apresentam várias hipóteses para justificar a seleção quiral dos aminoácidos:

[5] "Para explicar o fato de que todos os seres vivos conhecidos (...) utilizam quase exclusivamente L-aminoácidos em suas reações químicas, duas hipóteses foram sugeridas...”.

No TDC em questão as características implícitas da prática científica foram observadas quando os autores se referiram à atitude de surpresa dos cientistas com relação ao resultado de uma pesquisa [6] - sugerindo que os procedimentos científicos nem sempre surgem de estratégias bem pensadas e levam a resultados esperados -, incerteza das pesquisas científicas $[7,8]$ e ciência feita por trabalho em equipe $[9,10]$ :

[6] "Entretanto, o exame de aminoácidos de todos os seres vivos conhecidos revelou, para surpresa dos cientistas, que tais compostos estão presentes no organismo quase exclusivamente na forma de isômeros L".

[7] “D-aspartato e D-serina livres foram identificados em mamíferos e D-aminoácidos foram detectados em peptídeos opióides (...) e em neuropeptídeos (...) de outros animais, mas o papel fisiológico dessas substâncias ainda não é claro”. 
[8] "Os experimentos citados não permitem concluir qual deles foi o mais importante nessa seleção ou mesmo se algum deles teve alguma importância para o predomínio dos L-aminoácidos nos seres vivos”.

[9] "Na primeira situação, proposta a partir de experimentos de Robert Hazen e outros...”.

[10] "Foi observado, em experimentos de Pier Luigi Luisi e outros, na Suiça, que a polimerização de misturas racêmicas de aminoácidos...”.

\section{Abordagens e contexto}

Observamos que o TDC apresenta uma abordagem predominantemente conceitual, pois, embora trate de estudos científicos que melhor expliquem o fenômeno em pauta, demonstra que os autores têm intenção explícita em descrever as propriedades das moléculas de aminoácidos. Portanto, o TDC em questão está inserido em um contexto que pretende deixar o leitor minimamente informado a respeito dos assuntos abordados. Em menor medida, o texto apresenta enfoque científico, uma vez que apresenta os aspectos científicos inerentes ao assunto estudado, conforme exemplificado no tópico características da atividade científica.

\section{Estrutura}

Quanto à sua estrutura, o texto está disposto numa progressão lógica, o que impede uma leitura fragmentada do mesmo, ou seja, a leitura de partes independentes. $\mathrm{O}$ fato de haver no texto uma sequência de definições para seu melhor entendimento favorece essa unidade. A ausência de boxes reforça a impossibilidade de leitura segmentada do TDC.

\section{Recursos visuais e textuais}

No que diz respeito aos recursos visuais e textuais, o texto está escrito em 6 páginas e seu título também ocupa página dupla, destacado em letras grandes. Nas retrancas a área indicada é "Química" e a abertura do texto aparece na lateral esquerda da primeira página, com a referência autoral logo abaixo. Na segunda página o texto é iniciado, com a seguinte frase em destaque: "A grande maioria das reações químicas". O texto apresenta quatro intertítulos que anunciam os tópicos do texto já descritos nesta análise.

São encontradas 6 figuras no texto, sendo duas representações moleculares, duas representações esquemáticas e duas fotos de minerais. A primeira representação molecular ilustra a molécula de um aminoácido, com seus elementos constituintes dispostos em cores diferenciadas e uma legenda indicando a cor correspondente a cada elemento químico. Na legenda dessa figura encontra-se um procedimento explicativo sobre a estrutura química do aminoácido, corroborando o caráter conceitual do texto:

[11] "Os aminoácidos têm uma estrutura química comum, aqui representada pela alanina, um dos mais simples: um átomo de carbono 'central', ao qual se ligam um grupo amina $\left(\mathrm{NH}_{2}\right)$, um átomo de hidrogênio, um grupo carboxila $(\mathrm{COOH})$ e outro grupo químico, chamado de cadeia lateral ou grupo R. Nos demais aminoácidos a cadeia lateral é diferente".

A segunda representação molecular cumpre os mesmos objetivos de explicitação, a qual apresenta uma molécula e sua respectiva imagem especular, de modo a explicar a propriedade da quiralidade em aminoácidos. A primeira representação esquemática ilustra o exemplo das "mãos", bastante usado por professores e livros didáticos para explicar a quiralidade. A outra representação esquemática apresenta o mecanismo de funcionamento de um equipamento óptico usado para determinar o ângulo de rotação do plano. As figuras ilustram os minerais calcita e quartzo, respectivamente, descritos no texto como possíveis responsáveis pela 'seleção' quiral de aminoácidos em tempos remotos.

Na última página do TDC, no canto inferior direito, encontra-se um quadro com as "Sugestões para leitura", indicando três referências bibliográficas: um livro, dois artigos científicos de periódicos internacionais e um de periódico nacional.

\section{Linguagem}

O texto em pauta apresenta linguagem acessível, repleto de procedimentos explicativos para facilitar a compreensão do leitor. $\mathrm{O}$ recurso da definição é bastante usado no texto, de diferentes formas, conforme ilustram os exemplos a seguir:

[12] "Já as proteínas, essenciais para todos os organismos vivos, são constituídas por longas cadeias (...) de diferentes aminoácidos”.

[13] "Todos os aminoácidos (...) têm um centro quiral, ou seja, um átomo em torno do qual disposições diferentes dos outros componentes da estrutura da molécula formam os dois elementos do par assimétrico”.

[14] "Polarizar a luz significa selecionar (com prismas especiais) as ondas luminosas, deixando passar apenas as que oscilam em um determinado plano...”.

[15] "Na primeira situação (...) cristais de calcita (...) foram submetidos em uma solução contendo uma mistura racêmica de ácido aspártico (ou seja, com igual quantidades de formas dextrógira e levógira desse aminoácido)".

Exemplos do cotidiano também constituíram estratégia dos autores em aproximar o leitor do tema do texto e proporcionar sua compreensão:

[16] "No exemplo das mãos, a direita é uma imagem invertida da esquerda, como se uma fosse o reflexo da outra em um espelho. Isso também vale para os pés e para objetos como as asas de um avião".

[17] "Essa diferença nas propriedades pode ser importante em medicamentos, por exemplo, como no caso da talidomida, usada há algumas décadas para combater náuseas em mulheres grávidas. Apenas um dos isômeros (D) tinha esse efeito. $O$ outro $(L)$, como infelizmente muitas mães descobriram, antes que a quiralidade fosse bem conhecida, provocava graves malformações nos fetos".

O uso da nomeação também foi usado várias vezes no texto, que consiste em inserções acompanhadas de expressões do tipo: o processo chamado de..., a teoria chama de x... Vejamos alguns exemplos:

[18] "Eles são constituídos pelos elementos (...) e têm uma estrutura química comum: um átomo de carbono (chamado de carbono alfa) ligado a um grupo...”.

[19] "Os isômeros que desviam o plano da luz polarizada para a direita (...) são chamados de dextrógiros e representados pela letra $D . . . ”$.

[20] "Em uma reação química de síntese de aminoácidos, a partir de seus precursores, sempre obtemos o que é chamado de mistura racêmica, na qual cada isômero (D ou L) tem participação de 50\%”.

É possível observar nos casos apresentados que o termo que antecede o termo nomeado não é o científico, na tentativa dos autores de aproximar o leigo do que vai ser tratado. Após isso, o termo 
científico é inserido por meio da nomeação. Essa remissão ao termo científico é uma garantia de confiabilidade e uma tentativa dos autores em aproximar o leitor da linguagem científica.

Do mesmo modo observamos a intenção dos autores em aproximar o leitor da linguagem química propriamente dita, especialmente as representações químicas dos elementos e compostos, conforme exemplificamos nos trechos a seguir:

[21] "Eles são constituídos pelos elementos carbono $(C)$, hidrogênio $(H)$, oxigênio $(O)$, nitrogênio $(N)$...”.

[22] "A única exceção é a prolina, que no lugar da amina tem um grupo imino $\left(\mathrm{NH}^{-}\right)$, ligado não só ao carbono alfa mas também à cadeia lateral...”.

O uso de aspas foi também usado com frequência, sempre na tentativa de favorecer o entendimento do leitor acerca dos conteúdos tratados no texto:

[23] "Esse termo (...) faz referência a uma característica das mãos humanas e de certos objetos tridimensionais que existem em pares assimétricos, ou 'invertidos',".

Foram também observados casos de interlocução direta com o leitor, nos quais os autores convidam o leitor a participar das mesmas indagações com relação às lacunas dos estudos sobre o tema em foco:

[24] "Portanto, qual seria o efeito dos sais existentes na água do mar (na Terra primitiva) na seleção dos isômeros dos aminoácidos?"

[25] "Será que um dia encontraremos uma forma de vida extraterrestre que utilize D-aminoácidos? Por enquanto o mistério continua”.

\section{ANÁLISE DO ARTIGO INDICADO PELO NÚMERO 22 NA TABELA 1:}

\section{A qualidade do sedimento: contaminação por metais pode ser ameaça a seres vivos}

O texto intitulado "A qualidade do sedimento: contaminação por metais pode ser ameaça a seres vivos" é assinado por C. F. Mariani e M. L. M. Pompêo, do Departamento de Ecologia, da Universidade de São Paulo.

Apresentamos inicialmente a análise dos conteúdos específicos (temática, características da atividade científica e abordagens $e$ contextos) presentes no artigo e, em seguida, são evidenciados e discutidos os aspectos característicos concernentes à forma (estrutura, linguagem e recursos visuais e textuais).

\section{Temática}

A temática do texto envolve a importância dos sedimentos acumulados no fundo dos corpos d'água para o estudo desses ecossistemas e faz um alerta sobre os danos causados ao meio ambiente por substâncias tóxicas lançadas na água, que tendem a se depositar no sedimento.

Na introdução do artigo os autores definem o que é um sedimento e apresentam a importância dos estudos sobre sua composição e presença de agentes contaminantes, especialmente por metais pesados. O segundo tópico ("Avaliação da qualidade") alerta para a necessidade de discussões sobre a qualidade do sedimento e sobre os teores aceitáveis de contaminantes para evitar a toxicidade. O último tópico traz "O caso da represa Rio Grande" e os procedimentos usados para avaliar a qualidade de seu sedimento, uma vez que essa represa enfrenta problemas de contaminação de diversas fontes.

\section{Características da atividade científica}

As características da atividade científica presentes no artigo dizem respeito principalmente aos procedimentos realizados para avaliar a qualidade de sedimentos, desde o processo de coleta de dados [1], procedimentos de análise [2], à interpretação de resultados [3]:

[1] "Para avaliar a qualidade do sedimento, foram coletadas amostras em 29 pontos ao longo do eixo central da represa Rio Grande...”.

[2] “... e realizadas medições, no sedimento superficial (10cm iniciais) do teor dos metais cádmio, chumbo, zinco, cobre, cromo e níquel e do teor de sulfatos".

[3] "A comparação entre sulfetos e metais revelou haver excesso de sulfeto em todos os pontos amostrados, o que indica baixo potencial tóxico...”.

Ademais, os autores explicitam como são tiradas conclusões a respeito dos estudos sobre a presença de contaminantes em um sedimento e se este pode ser considerado poluído:

[4] "O mais indicado, quando é preciso concluir se um sedimento é ou não poluído, tem sido coletar diferentes tipos de dados e, após uma análise conjunta, tomar a decisão de interferir ou não no local para amenizar os efeitos da poluição”.

É interessante notar que os autores se baseiam em valores obtidos em outros estudos para validar seus resultados [5] e colocam a necessidade de realizar procedimentos de análise complementares para uma avaliação mais acurada a respeito dos mesmos [6], evidenciando as limitações dos procedimentos científicos apresentados:

[5] "De fato, outros trabalhos realizados no Rio Grande encontraram teores de metais superiores aos de sulfeto, o que indica uma mudança possivelmente sazonal".

[6] “... é necessário, para uma avaliação mais acurada dos riscos potenciais para a saúde pública da contaminação da água dessa represa, usar métodos complementares de medição dos poluentes e de seus efeitos".

O último ponto concernente a essa categoria que destacamos diz respeito à figura apresentada no TDC que apresenta três fotos em sequência, ilustrando o procedimento de coleta de um sedimento para análise.

\section{Abordagens e contexto}

Observamos que o TDC em pauta possui uma abordagem essencialmente ambiental, pois os autores apresentam toda a descrição a respeito dos estudos que envolvem a qualidade dos sedimentos, baseados em argumentos que evocam a problemática ambiental decorrente de sua contaminação. Consideramos que o assunto em questão também é abordado dentro de um contexto científico, uma vez que as evidências científicas fazem parte da estratégia dos autores em convencer ao leitor sobre a questão tratada no TDC.

\section{Estrutura}

O TDC pressupõe uma leitura sequenciada, uma vez que apresenta uma sucessão de informações interdependentes, ou seja, inicialmente coloca-se a definição sobre o que é o sedimento, em seguida descreve-se como é realizada a avaliação da qualidade desse sedimento e, por fim, apresenta-se o estudo de um caso específico. Dessa forma, a progressão da leitura é necessária para o adequado entendimento do texto. 


\section{Recursos visuais e textuais}

O TDC está escrito em seis páginas e nas retrancas a área indicada é "Limnologia". O conteúdo do subtítulo - "Contaminação por metais pode ser ameaça aos seres vivos" - permite ao leitor vislumbrar o teor do TDC. Assim como nos demais textos analisados, a abertura aparece na lateral esquerda da primeira página, com a referência autoral logo abaixo. Na segunda página o texto é iniciado com a seguinte frase em destaque: "Sedimento é todo tipo de depósito formado por partículas". O texto apresenta dois intertítulos que anunciam os tópicos mencionados.

São encontradas seis figuras no texto: uma representação esquemática, dois gráficos e três fotos. A representação esquemática ilustra os diferentes processos físicos, químicos e biológicos que ocorrem em um sedimento e na sua interface com a água. Os gráficos apresentam dados relativos à avaliação da qualidade em sedimentos. Duas das três fotos retratam a represa Rio Grande e a última diz respeito ao procedimento de coleta do sedimento.

Na última página do TDC, no canto inferior direito, encontra-se um quadro com as "Sugestões para leitura", indicando cinco referências bibliográficas: dois livros e uma dissertação de mestrado (nacionais); duas páginas da internet relativas às Agências de Proteção Ambiental do Canadá e Estados Unidos, respectivamente.

\section{Linguagem}

O texto em pauta apresenta linguagem acessível que, apesar de enfatizar procedimentos científicos, coloca o assunto dentro de um contexto ambiental, apresentando tom de conscientização e alerta por parte do leitor com relação às consequências ambientais da contaminação de sedimentos por metais pesados. Por esse motivo, os autores fizeram uso de diversas estratégias para fornecer os conhecimentos necessários ao leitor para o entendimento sobre a problemática tratada. Esses conhecimentos foram transmitidos principalmente sob a forma de definição e procedimentos explicativos, conforme ilustramos a seguir:

[7] "Sedimento é todo tipo de depósito formado por partículas - de natureza mineral ou biológica - transportadas por fluidos, principalmente a água e o ar".

[8] "Os contaminantes são compostos químicos presentes no ambiente em teores acima dos naturais. Eles tornam-se poluentes se sua quantidade (ou sua forma) possibilitar sua ingestão ou incorporação por seres vivos do ambiente aquático...".

Observamos que os autores constroem uma narrativa dentro da perspectiva da preservação dos ambientes aquáticos, com o intuito de envolver o leitor na questão apresentada e demonstrar a importância do assunto: [9] "Os problemas causados por metais e outros compostos tóxicos atingem organismos aquáticos e populações humanas que consomem a água não tratada adequadamente e o pescado obtido na área contaminada”.
[10] "Por isso é necessária a discussão sobre a qualidade do sedimento e sobre os teores aceitáveis de contaminantes para evitar a toxicidade".

O uso de valores numéricos para exemplificar o teor dos contaminantes analisados nas amostras de sedimento, assim como a comparação com valores de referência ("VRR"), representa a intenção dos autores em favorecer a percepção do leitor quanto aos resultados apresentados:

[11] "O maior destaque foi o cobre, para o qual foi obtido um teor médio de 1.848,84 miligramas por quilo $(\mathrm{mg} / \mathrm{Kg})$ de sedimento, valor 102,7 vezes maior que o VRR...”.

[12] "Nos casos de cromo e zinco, os teores encontrados foram $46 \%$ e 30\% maiores que o VRR, respectivamente, enquanto o de níquel ficou quase três vezes acima do VRR".

A busca de credibilidade em outros estudos se constitui uma característica marcante no texto. Verificamos que os autores se apóiam em diversas fontes para consolidar os dados apresentados:

[13] “... outros trabalhos realizados no Rio Grande encontraram teores de metais...”.

[14] “A comparação (...) dos resultados do nosso estudo com um levantamento feito em 2004 pela Companhia de Tecnologia de Saneamento Ambiental do Estado de São Paulo...”.

Por fim, salientamos a questão trazida pelos autores para o TDC, a respeito da construção do Rodoanel (anel viário ao redor da cidade de São Paulo) e suas consequências para os sedimentos da represa Rio Grande. Entendemos ser esta mais uma forma de aproximar o leitor do texto, uma vez que representa um assunto de interesse direto:

[15] "No traçado atual, o trecho sul do Rodoanel passa pela área do complexo Billings e está prevista a implantação de pilares de sustentação de viadutos dentro da represa Rio Grande, o que poderá ressuspender os metais hoje depositados no sedimento, comprometendo a qualidade da água para usos múltiplos".

[16] "Os dados levantados na represa Rio Grande servem como um sinal de alerta e demonstram que é necessário estabelecer um amplo programa de monitoramento para avaliar não só alterações na qualidade da água, mas também o padrão espacial e sazonal dos teores de metais no sedimento".

Tendo em vista as características apresentadas, consideramos que os autores fizeram uso do espaço do TDC em foco para transmitir informações ao leitor a respeito de questões ambientais, por meio da explicitação de evidências científicas. 